\title{
Risk Factors of Glycaemia Control among Children and Adolescents with Type 1 Diabetes in Basra City/Iraq
}

\author{
Shukur Abdulkareem Mahmood ${ }^{1}$, Majid A. Maatook ${ }^{2}$, Dhaigham E. Aatwan ${ }^{3}$ \\ \{ shukurcomm@gmail.com ${ }^{1}$, m.maatook@stud.edu.iq² dhaigh1977@gmail.com ${ }^{3}$ \} \\ Southern Technical University/College of Health \& Medical Technology, Basra/Iraq ${ }^{1,2}$ \\ Al Basra Health Directorate/Faiha Specialized Diabetes, Endocrine, and Metabolism Centre/Iraq ${ }^{3}$
}

\begin{abstract}
Little is known about risk factors and levels of glycaemic control for poorcontrolled hyperglycaemia in Iraq children and adolescents with type 1 diabetes mellitus. The study aims to determine the glycaemic control and risk factors of poor control hyperglycaemia in children and adolescents with type 1 diabetes mellitus patients. A crosssectional study was 209 type 1 diabetics. Glycaemic control of type 1 diabetes varies widely among children and adolescents in Basra/Iraq, risking microvascular complications. Only (36) $17.2 \%$ of children and adolescents with type 1 diabetes mellitus were good-controlled diabetes, (25) 69.4\%, was compliance with insulin therapy in goodcontrolled type 1 diabetes mellitus patients, females were higher than males and in the age group (1-6) years, higher than the other age groups. The major risk factors for poorcontrolled hyperglycaemia are noncompliance with insulin therapy, not checking daily glucometer blood glucose and irregular clinic visits for follow-up.
\end{abstract}

Keywords: Glycaemic Control, Adolescents, Children, Insulin, Basra City.

\section{Introduction:}

Diabetes is a chronic disease of huge morbidity and mortality; regular medical treatments and self-entraining are needed to ensure optimum glycaemic control that is critical in decreasing the long-term risk of diabetes-related complications and mortality [1]. Good-controlled patients with type 1 diabetes mellitus in paediatric patients are critical not only for reducing complications and delaying progression but also for normal growth and development [2]. However, glycaemic regulation is insufficient in the majority of clinical settings. According to one study, only $37 \%$ of adults with diabetes mellitus have an HbA1c level of 7\% [3]. Further, in one paediatric study, the mean level of HbAlc was found to be $8.8 \%$ [4], indicating that the majority of children did not meet the recommended target level of HbAlc less than 7.5\% [5]. Poor-controlled hyperglycaemia may be caused by failure to take medication on time, eat too much and exercise too little. Some episodes of hyperglycaemia occur for no apparent cause. Illness may also cause a rise in blood glucose levels. Hyperglycaemia can damage the kidneys, nerves, blood vessels, eyes, teeth, and gums over time [6]. Hyperglycaemia-related neurocognitive complications have also been reported [7]. During a nationwide Iraq project conducted between 1 January 2012 and 31 December 2016, 818 new cases of type 1 diabetes were found, coinciding with a worldwide rise in the incidence of diabetes. Males made up 417 of these $(50 \%)$. The annual incidence rate of type 1 diabetes was 7.4 per 100,000, and the prevalence rate of type 1 diabetes in people aged less than 40 was 87 per 100,000 in 2016 [8]. However, few studies in Iraqi children and adolescents with glycaemic control scale type 1 diabetes as well as risk factors associated with uncontrolled hyperglycaemia have been carried out in Iraq.

\section{Methods}

A cross-sectional study was carried out from 1st. September 2020 until the 15th. May of 2021 to determine the glycaemic control and risk factors of poor control hyperglycaemia in children and adolescents with type 1 diabetes mellitus in Basra city, for the study sample which 
was 209 type 1 diabetics, selected randomly from the visitors of a Faiha Specialized Diabetes, Endocrine, and Metabolism Centre (FDEMC). The American Diabetes Association assigned target HbA1c levels to patients based on their age groups. A comparison has been made between good-controlled patients and poor-controlled hyperglycaemia patients. To assess each risk factor's role in uncontrolled type 1 diabetes hyperglycaemia, the Odds Ratios, was calculated. At the time of the study, we followed the American Diabetes Association (ADA) 2014 Guidelines. The data of all patients were obtained from interview patients and the digital records of (FDEMC) as it has an internal network system and Microsoft Access program for documenting all patients' information and investigations. Statistical analysis: Together, study data are shown as frequency and percentages $(\%)$. The variations between the groups of the study were established by the Chi-square test, the Odds Ratios were calculated. Statistical significance is designated by a value of $\mathrm{P}$. $<0.05$. All statistical investigates were attained by utilizing IBM SPSS (version 25).

\section{Results}

\subsection{Distribution of the Glycaemic Control of the Sample}

The study included a total of 209 type 1 diabetic,36 (17.2\%) with good-controlled diabetes and $173(82.8 \%)$ with poor-controlled hyperglycaemia diabetes, who were already diagnosed as type 1 diabetes mellitus as shown in Fig 1.

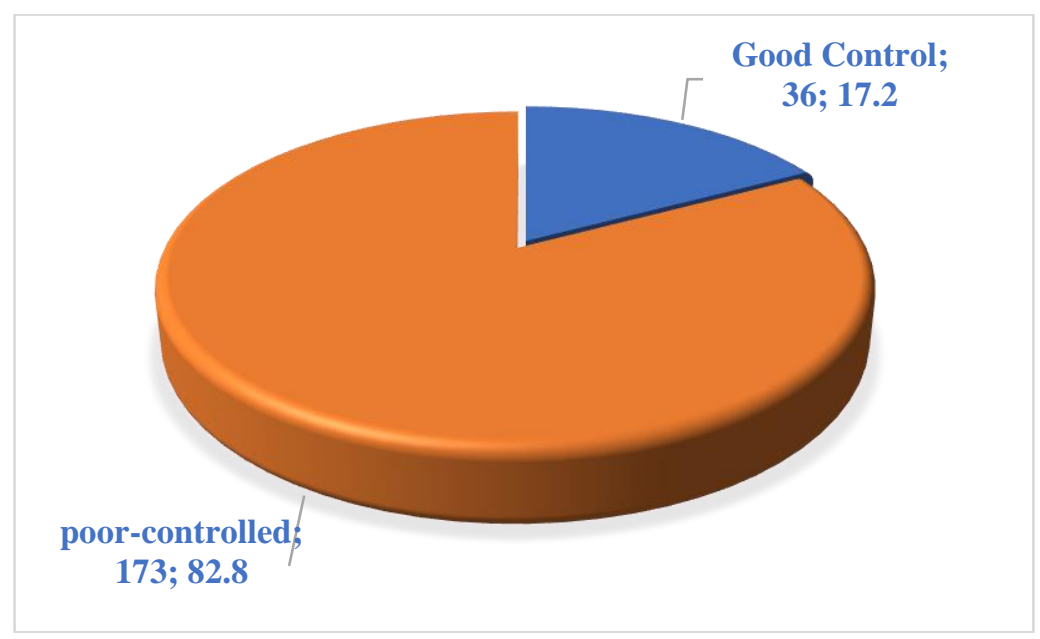

Fig 1. Distribution of the glycaemic control of the sample.

\subsection{Distribution Glycaemic Control According to the Age Group of the Sample}

A total of 209 types 1 diabetic, 108 (51.7\%) males and 101 (48.3\%) females who are already diagnosed as type 1 diabetes patients aged $(2-18)$ years were included in the present study. The results show that the patient's males, $59(54.6 \%)$ in $(13-18)$ years and females, $44(43.6 \%)$ in $(13-18)$ years as appear in Fig 2. 


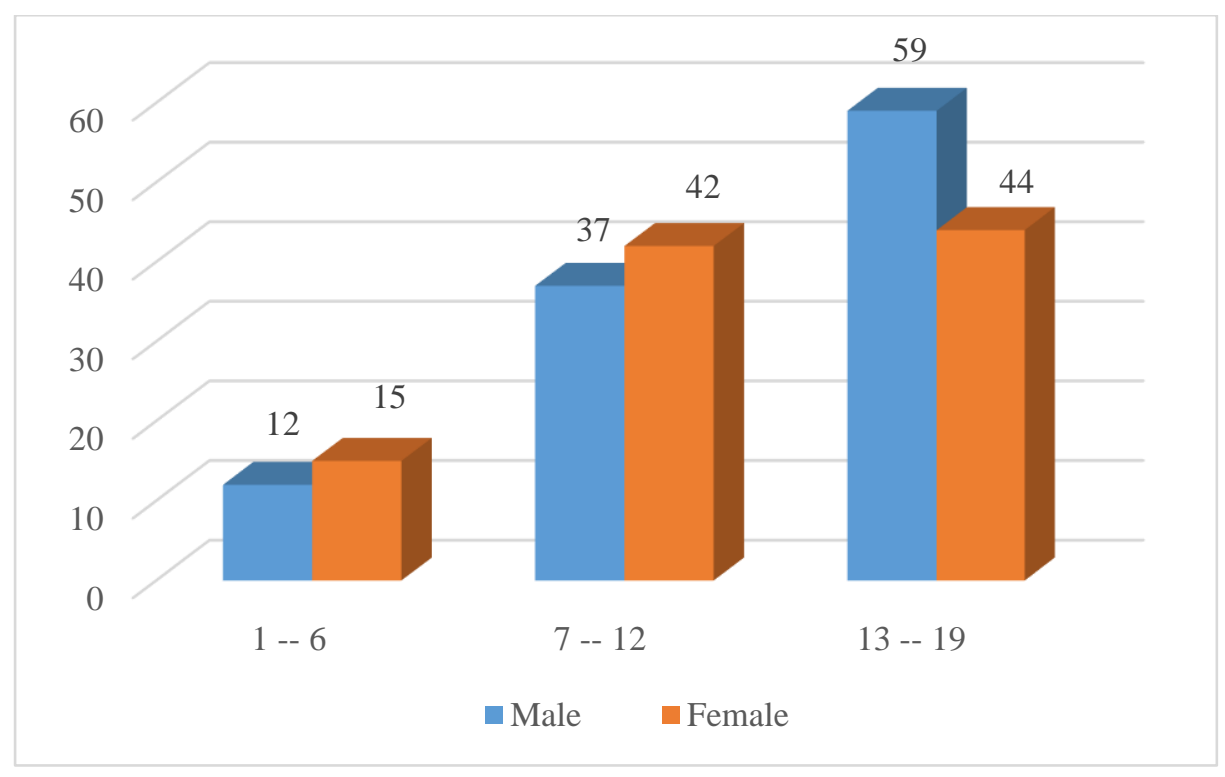

Figure 2. Distribution of the gender according to age grouping of the sample.

\subsection{Distribution Educational Level of Patients and Patients' Parents According to Glycaemic Control of the Sample}

The distribution educational level of patients and patients' parents according to Glycaemic Control is represented in Table 1 .

The present study found that in poor-controlled hyperglycaemia type 1 diabetes patients, 77 $(44.5 \%)$ had secondary school level, $12(6.9 \%)$ uneducated patients, whereas in good-controlled diabetes with type 1 diabetes patients, $15(41.7 \%)$ had a primary school level, $2(5.6 \%)$, uneducated patients. Regarding parents' education levels, the present study found that among uncontrolled hyperglycaemia diabetes T1DM (paternal) patients $96(55.5 \%)$ had a primary school, 35 (20.2\%) high educated level (university), whereas in well control diabetes with T1DM paternal patients $16(44.4 \%)$ had a primary school, $4(11.2 \%)$ was secondary school level, 16 (44.4\%) high educated level (university). According to parents' education levels, the present study found that among uncontrolled hyperglycaemia diabetes T1DM (maternal) patients $1(0.5 \%)$ uneducated, $116(67.1 \%)$ had a primary school, whereas in well control diabetes with T1DM paternal patients, $15(41.7 \%)$ was secondary school level, $7(19.4 \%)$ high educated level (university) as shown in Table 1.

Table 1. Distribution educational level of patients and patient's parents according to Glycaemic Control of the sample:

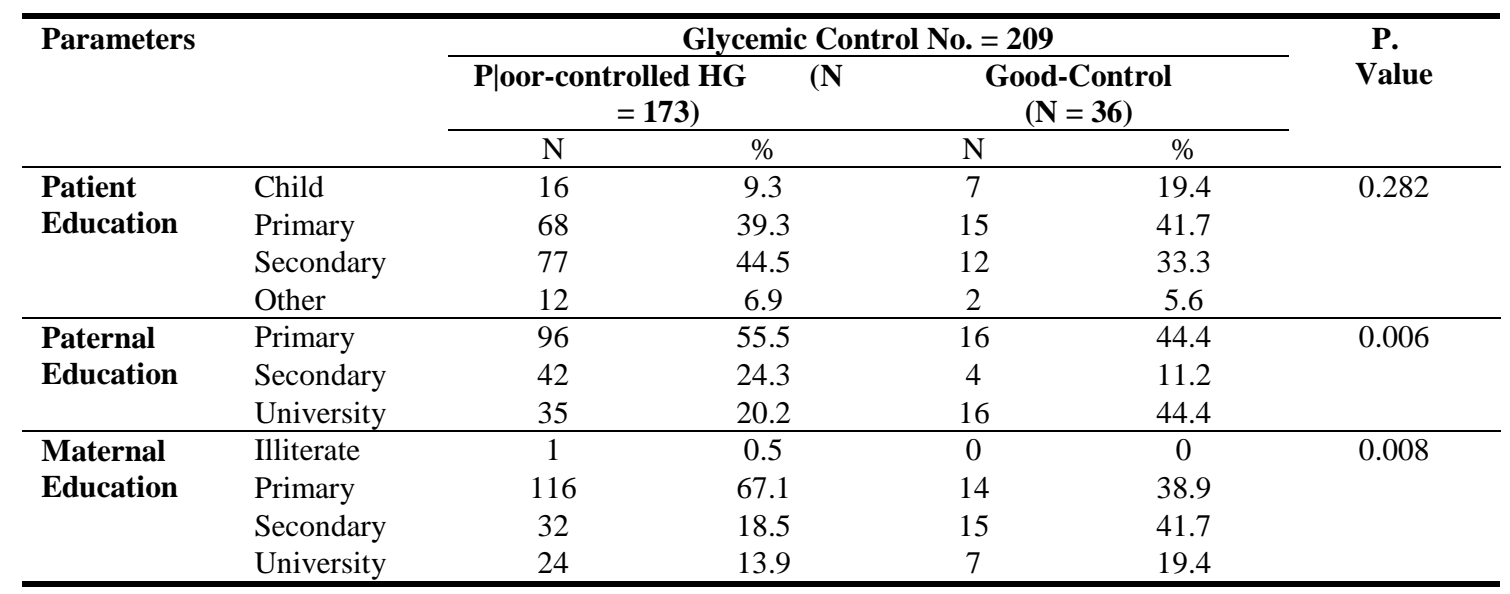




\subsection{Distribution Monitoring of Hba1c, Blood Sugar and Medical Follow-Up of T1DM According to Glycaemic Control of the Sample}

According to blood glucose level checking daily, this shows that in poor-controlled hyperglycaemia type 1 diabetes patients, 106 (61.3\%) unchecking blood glucose level daily, whereas, in good-controlled type 1 diabetes patients, 25 (69.4\%) check blood glucose level daily. Regarding the monitoring of $\mathrm{HbA1c}$, this shows that in poor-controlled hyperglycaemia type 1 diabetes patients, 113 (65.3\%) check HbAlc every three months, whereas, in goodcontrolled type 1 diabetes patients, 35 (97.2\%) checking HbA1c every three months.

Regarding the monitoring of ketone in urine, this shows that in poor-controlled hyperglycaemia type 1 diabetes patients, $118(68.2 \%)$ had not checked ketone in urine, whereas, in goodcontrolled type 1 diabetes patients, $20(55.6 \%)$ check ketone in urine. According to regular medical follow-up, this shows that in poor-controlled hyperglycaemia type 1 diabetes patients, $131(75.7 \%)$ lack regular clinic visits for medical follow-up, whereas, in good-controlled type 1 diabetes patients, 32 (88.9\%) had regular clinic visits for medical follow-up.

Regarding availability for a telephone consultation, this shows that in poor-controlled hyperglycaemia type 1 diabetes patients, 155 (89.6\%) unavailability for a telephone consultation, whereas, in good-controlled type 1 diabetes patients, $13(36.1 \%)$ availability for a telephone consultation, $23(63.9 \%)$ unavailability for a telephone consultation. According to diabetes-related education received, this shows that in poor-controlled hyperglycaemia type 1 diabetes patients, $69(39.9 \%)$ received education from an endocrinologist, $54(31.2 \%)$ did not receive any education from another person, whereas, in good-controlled type 1 diabetes patients, $28(77.8 \%)$ received educated from an endocrinologist, $1(2.8 \%)$ not received any educated from another person as appears in Table 2.

Table 2. Distribution monitoring of HbA1c, blood sugar and medical follow-up of T1DM according to Glycaemic Control.

\begin{tabular}{|c|c|c|c|c|c|c|c|c|}
\hline \multirow{3}{*}{\multicolumn{2}{|c|}{ Parameters }} & & \multicolumn{4}{|c|}{ Glycemic Control No. $=209$} & \multirow[t]{3}{*}{ OR(95\% CI) } & \multirow{3}{*}{$\begin{array}{c}P . \\
\text { Value }\end{array}$} \\
\hline & & & \multicolumn{2}{|c|}{$\begin{array}{l}\text { P|oor-controlled } \\
\text { HG }(\mathbf{N}=173)\end{array}$} & \multicolumn{2}{|c|}{$\begin{array}{l}\text { Good-Control } \\
(\mathrm{N}=36)\end{array}$} & & \\
\hline & & & $\mathrm{N}$ & $\%$ & $\mathrm{~N}$ & $\%$ & & \\
\hline \multirow{2}{*}{\multicolumn{2}{|c|}{$\begin{array}{l}\text { Do you daily glucometer } \\
\text { blood glucose check? }\end{array}$}} & Yes & 67 & 38.7 & 25 & 69.4 & $0.28(0.13-0.6)$ & 0.001 \\
\hline & & No & 106 & 61.3 & 11 & 30.6 & - & \\
\hline \multirow{2}{*}{$\begin{array}{l}\text { Monitor } \\
\text { HbA1c }\end{array}$} & \multicolumn{2}{|c|}{ Every 3 months } & 113 & 65.3 & 35 & 97.2 & $0.05(0.01-0.4)$ & $<0.001$ \\
\hline & \multicolumn{2}{|c|}{ Every 6 months } & 60 & 34.7 & 1 & 2.8 & - & \\
\hline \multirow{2}{*}{\multicolumn{2}{|c|}{$\begin{array}{l}\text { Do you check your urine for } \\
\text { ketones? }\end{array}$}} & Yes & 55 & 31.8 & 20 & 55.6 & $0.37(0.18-0.78)$ & 0.007 \\
\hline & & No & 118 & 68.2 & 16 & 44.4 & - & \\
\hline \multirow{2}{*}{\multicolumn{2}{|c|}{$\begin{array}{l}\text { Do you regular clinic visits } \\
\text { for follow-up }\end{array}$}} & Yes & 42 & 24.3 & 32 & 88.9 & $0.04(0.01-0.12)$ & $<0.001$ \\
\hline & & No & 131 & 75.7 & 4 & 11.1 & - & \\
\hline \multirow{2}{*}{\multicolumn{2}{|c|}{$\begin{array}{l}\text { Availability for telephone } \\
\text { consultation }\end{array}$}} & Yes & 18 & 10.4 & 13 & 36.1 & $0.19(0.07-0.54)$ & $<0.001$ \\
\hline & & No & 155 & 89.6 & 23 & 63.9 & - & \\
\hline \multirow{6}{*}{$\begin{array}{l}\text { Diabetes } \\
\text { related } \\
\text { education } \\
\text { received } \\
\text { from }\end{array}$} & \multicolumn{2}{|c|}{ Family Physician } & 6 & 3.5 & 0 & 0 & - & $<0.001$ \\
\hline & \multicolumn{2}{|l|}{ Endocrinologist } & 69 & 39.9 & 28 & 77.8 & - & \\
\hline & \multicolumn{2}{|l|}{ Nurse } & 16 & 9.2 & 0 & 0 & - & \\
\hline & \multicolumn{2}{|l|}{ Nutritionist } & 2 & 1.2 & 0 & 0 & - & \\
\hline & \multicolumn{2}{|l|}{ Internet } & 26 & 15.0 & 7 & 19.4 & - & \\
\hline & \multicolumn{2}{|l|}{ No Education } & 54 & 31.2 & 1 & 2.8 & - & \\
\hline
\end{tabular}

\subsection{Relationship Between Insulin Therapy Characteristics and Glycaemic Control of the Sample}

According to the insulin regimen, 64 (94.8\%), using multiple injections of insulin injections daily in poor-controlled hyperglycaemia type 1 diabetes patients, whereas 8 (22.2\%), using twice injections of insulin injections daily in good-control type 1 diabetes patients, with a significant statistical difference between poor-controlled hyperglycaemia type 1 diabetes patients, and good-control type 1 diabetes patients, was found $(\mathrm{P} .=0.001)$. The present study found that the type of insulin injection used in poor-controlled hyperglycaemia type 1 diabetes patients, $133(76.1 \%)$ was vial injection, whereas in good-control type 1 diabetes patients, 31 $(86.1 \%)$ vial injection, the results showed no significant statistical difference between goodcontrol diabetes and poor-controlled hyperglycaemia diabetes was found $(P=0.22)$. The current study discovered that the way of insulin storage in poor-controlled hyperglycaemia type 
1 diabetes patients, $168(97.1 \%)$, was good storage of insulin through the transformation from the centre to home, whereas in good-controlled type 1 diabetes patients, $32(88.9 \%)$. The current study discovered that compliance with insulin therapy in poor-controlled hyperglycaemia type 1 diabetes patients was 146 (84.4\%), whereas compliance with insulin therapy in good-controlled type 1 diabetes patients was $25(69.4 \%)$.

The present study found that injection areas that are often used in insulin injection therapy, in poor-controlled hyperglycaemia type 1 diabetes patients, $83(48.0 \%)$ was insulin injection in the arm with insulin therapy, whereas, in good-controlled type 1 diabetes patients, $18(50.0 \%)$ was the insulin therapy injection in the more than site, the results showed no significant statistical difference between good-controlled type 1 diabetes and poor-controlled hyperglycaemia type 1 diabetes was found $(P=0.854)$. The current study found that the rotation sites with each insulin injection, in diabetic patients with poor-controlled type 1 diabetes patients, $118(68.2 \%)$ did not have a rotation position with each insulin injection treatment, while in diabetics who were good-controlled type 1 diabetes patients, $18(50.0 \%) \%)$ The site was rotated with each insulin injection treatment, the results showed a significant statistical difference between good-controlled type 1 diabetes and poor-controlled hyperglycaemia type 1 diabetes was found $(\mathrm{P} .=0.037)$.

According to the insulin injector among patients with poor-controlled hyperglycaemia of type 1 diabetes patients, $82(47.4 \%)$ was patients self-injected, $90(52.0 \%)$ was injected by parents, $1(0.6 \%)$ was injected by others, while in the control condition of diabetes with type 1 diabetes patients $11(30.6 \%)$ was patients self-injected $25(69.4 \%)$ was injected by the parent. The results showed no significant statistical difference between good-controlled type 1 diabetes patients, and poor-controlled hyperglycaemia type 1 diabetes patients, was found $(\mathrm{P}=0.153)$.

According to the educational level of insulin injector among patients with poor-controlled hyperglycaemia of type 1 diabetes, $84(48.6 \%)$ had a primary school, $76(43.9 \%)$ was at the secondary school level, $13(7.5 \%)$ High educational level (university), while in the control condition of diabetes with type 1 diabetes patients $12(33.3 \%)$ had a primary school, 17 (47.3\%) was at the secondary school level, 7 (19.4\%) High level of education (university).

Regarding the educational level of insulin injectors in poor-controlled hyperglycaemia type 1 diabetes patients and good-controlled type 1 diabetes patients, the results showed a significant statistical difference between poor-controlled hyperglycaemia type 1 diabetes patients and good-controlled type 1 diabetes patients, $(\mathrm{P} .=0.05)$.

Table 3. Relationship between Insulin therapy characteristics and Glycaemia control:

\begin{tabular}{|c|c|c|c|c|c|c|c|}
\hline \multirow{3}{*}{\multicolumn{2}{|c|}{ Parameters }} & \multicolumn{4}{|c|}{ Glycemic Control No. $=209$} & \multirow[t]{3}{*}{ OR(95\% CI $)$} & \multirow{3}{*}{$\begin{array}{c}\text { P. } \\
\text { Value }\end{array}$} \\
\hline & & \multicolumn{2}{|c|}{$\begin{array}{l}\text { P|oor-controlled } \\
\text { HG } \quad(N=173)\end{array}$} & \multicolumn{2}{|c|}{$\begin{array}{c}\text { Good-Control } \\
(\mathbf{N}=36)\end{array}$} & & \\
\hline & & $\mathrm{N}$ & $\%$ & $\mathrm{~N}$ & $\%$ & & \\
\hline \multirow{2}{*}{$\begin{array}{l}\text { Types of insulin } \\
\text { regimen }\end{array}$} & Twice Daily & 9 & 5.2 & 8 & 22.2 & $0.19(0.07-0.54)$ & 0.001 \\
\hline & Multiple daily & 164 & 94.8 & 28 & 77.8 & - & \\
\hline \multirow{2}{*}{$\begin{array}{l}\text { Type of } \\
\text { insulin }\end{array}$} & Pen & 40 & 13.9 & 5 & 13.9 & $1.87(0.68-5.11)$ & 0.220 \\
\hline & Vial & 133 & 76.1 & 31 & 86.1 & - & \\
\hline \multirow[t]{3}{*}{ Syringe reuse } & Every injection & 21 & 12.2 & 12 & 33.3 & - & 0.002 \\
\hline & Every $2-3$ injections & 58 & 33.5 & 14 & 38.9 & - & \\
\hline & More 4 injections & 94 & 54.3 & 10 & 27.8 & - & \\
\hline \multirow{2}{*}{$\begin{array}{l}\text { Way of storage } \\
\text { insulin }\end{array}$} & Good & 168 & 97.1 & 32 & 88.9 & $4.20(1.07-16.5)$ & 0.027 \\
\hline & $\mathrm{Bad}$ & 5 & 2.9 & 4 & 11.1 & - & \\
\hline \multirow{2}{*}{$\begin{array}{l}\text { Compliance with } \\
\text { insulin therapy }\end{array}$} & Yes & 146 & 84.4 & 25 & 69.4 & $2.38(1.05-5.4)$ & 0.034 \\
\hline & No & 27 & 15.6 & 11 & 30.6 & - & \\
\hline \multirow{4}{*}{$\begin{array}{l}\text { Injection areas } \\
\text { that are often } \\
\text { used: }\end{array}$} & Arm & 83 & 48.0 & 16 & 44.4 & - & 0.854 \\
\hline & Thigh & 9 & 5.2 & 1 & 2.8 & - & \\
\hline & Abdomen & 6 & 3.5 & 1 & 2.8 & - & \\
\hline & More than 1 site & 75 & 43.3 & 18 & 50.0 & - & \\
\hline \multirow{2}{*}{\multicolumn{2}{|c|}{$\begin{array}{l}\text { Do you rotate sites } \\
\text { with each injection? }\end{array}$}} & 55 & 31.8 & 18 & 50.0 & $0.47(0.23-0.97)$ & 0.037 \\
\hline & & 118 & 68.2 & 18 & 50.0 & - & \\
\hline \multirow{4}{*}{ Insulin injector } & Patient & 82 & 47.4 & 11 & 30.6 & - & 0.153 \\
\hline & Parent & 90 & 52.0 & 25 & 69.4 & - & \\
\hline & Other & 1 & 0.6 & 0 & 0 & - & \\
\hline & Primary & 84 & 48.6 & 12 & 33.3 & - & 0.050 \\
\hline
\end{tabular}




\begin{tabular}{llccccc}
\hline Educational level & Secondary & 76 & 43.9 & 17 & 47.2 & - \\
of insulin injectors & University & 13 & 7.5 & 7 & 19.5 & - \\
\hline
\end{tabular}

\section{Discussion}

The study included a total of 209 type 1 diabetic,36 (17.2\%) with good-controlled diabetes and $173(82.8 \%)$ with poor-controlled hyperglycaemia diabetes, who were already diagnosed as type 1 diabetes mellitus patients and corresponds with the study [9]. Diabetic patients with poor-controlled hyperglycaemia diabetes are at a higher risk of complications, such as cardiovascular disease, even at a young age, and have a poorer health-related quality of life than non-diabetic patients [9]. The present study found that in poor-controlled hyperglycaemia type 1 diabetes patients, 77 (44.5\%) had secondary school level, 12 (6.9\%) uneducated patients, whereas in good-controlled diabetes with type 1 diabetes patients, $15(41.7 \%)$ had a primary school level, $2(5.6 \%)$, uneducated patients, the results showed that no significant statistical difference between well-controlled diabetes with T1DM patients and uncontrolled hyperglycaemia diabetes T1DM patients was found $(\mathrm{P} .=0.282)$. The results showed that a significant statistical difference between well-controlled diabetes with T1DM patients and uncontrolled hyperglycaemia diabetes with T1DM patients was found (P. =0.006); (P. =0.008) and corresponds with a study by [9]. According to blood glucose level checking daily, this shows that in poor-controlled hyperglycaemia type 1 diabetes patients, 106 (61.3\%) unchecking blood glucose level daily, whereas, in good-controlled type 1 diabetes patients, 25 (69.4\%) check blood glucose level daily. The results showed a significant statistical difference between poor-controlled hyperglycaemia and good-controlled type 1 diabetes patients $(P .=0.001)$ in agreement with this study [10]. Regarding the monitoring of HbA1c, this shows that in poorcontrolled hyperglycaemia type 1 diabetes patients, $113(65.3 \%)$ check HbA1c every three months, whereas, in good-controlled type 1 diabetes patients, 35 (97.2\%) checking HbA1c every three months.

The results showed a significant statistical difference between poor-controlled hyperglycaemia and good-controlled type 1 diabetes patients (P. < 0.001) which is confirmed with this study [11]. Regarding the monitoring of ketone in urine, this shows that in poor-controlled hyperglycaemia type 1 diabetes patients, $118(68.2 \%)$ had not checked ketone in urine, whereas, in good-controlled type 1 diabetes patients, $20(55.6 \%)$ check ketone in urine.

The results showed a significant statistical difference between poor-controlled hyperglycaemia and good-controlled type 1 diabetes patients $(P .=0.007)$ which agrees with this study [12]. According to regular medical follow-up, this shows that in poor-controlled hyperglycaemia type 1 diabetes patients, 131 (75.7\%) lack regular clinic visits for medical follow-up, whereas, in good-controlled type 1 diabetes patients, 32 (88.9\%) had regular clinic visits for medical follow-up. The results showed a significant statistical difference between poor-controlled hyperglycaemia and good-controlled type 1 diabetes patients $(\mathrm{P} .<0.001)$ which agrees with this study [9]. Regarding availability for a telephone consultation, this shows that in poorcontrolled hyperglycaemia type 1 diabetes patients, $155(89.6 \%)$ unavailability for a telephone consultation, whereas, in good-controlled type 1 diabetes patients, $13(36.1 \%)$ availability for a telephone consultation, $23(63.9 \%)$ unavailability for a telephone consultation. The results showed a significant statistical difference between poor-controlled hyperglycaemia and goodcontrolled type 1 diabetes patients (P. < 0.001) which agrees with this study [9]. According to diabetes-related education received, this shows that in poor-controlled hyperglycaemia type 1 diabetes patients, 69 (39.9\%) received education from an endocrinologist, 54 (31.2\%) did not receive any education from another person, whereas, in good-controlled type 1 diabetes patients, $28(77.8 \%)$ received educated from an endocrinologist, $1(2.8 \%)$ not received any educated from another person. The findings revealed a significant statistical difference between poor-controlled hyperglycaemia and good-controlled type 1 diabetes patients $(\mathrm{P}$. $<0.001)$. This may be attributed to a continued lack of public knowledge about diabetes mellitus in children, as well as among primary healthcare providers [10]. According to the insulin regimen, 64 $(94.8 \%)$, using multiple injections of insulin injections daily in poor-controlled hyperglycaemia type 1 diabetes patients, whereas 8 (22.2\%), using twice injections of insulin injections daily in good-control type 1 diabetes patients. This result shows that the insulin regimens in poorcontrolled hyperglycaemia type 1 diabetes patients, were higher than in good-controlled type 1 diabetes patients, with a significant statistical difference between good-controlled diabetes and poor-controlled hyperglycaemia diabetes was found $(\mathrm{P} .=0.001)$, which agrees with other 
studies like these by [13],[15]. Traditional insulin regimens of two insulin injections a day, on the other hand, can still be an effective therapeutic choice for children under the age of six, particularly for families who cannot afford intensive insulin therapy.

The present study found that the type of insulin injection used in poor-controlled hyperglycaemia type 1 diabetes patients, 133 (76.1\%) was vial injection, whereas in goodcontrol type 1 diabetes patients, $31(86.1 \%)$ vial injection, the results showed no significant statistical difference between good-control diabetes and poor-controlled hyperglycaemia diabetes was found $(\mathrm{P}=0.22)$. Compared with patients who used pen insulin injection, had 1.87 times $(95 \% \mathrm{CI}=0.68-5.11)$ higher odds of poor-controlled hyperglycaemia diabetes patients, and good-controlled diabetes patients, an indicator of high risk for poor-controlled hyperglycaemia diabetes. The present study found that the times type of reuses insulin syringes every injection in poor-controlled hyperglycaemia diabetes patients, 94 (54.3\%) was insulin syringe reuses 4 times or more than the injection, whereas, in good-controlled diabetes patients, $14(38.9 \%)$ insulin syringe reuses every $2-3$ injections, the results showed a significant statistical difference between good-controlled diabetes and poor-controlled hyperglycaemia diabetes was found $(\mathrm{P}=0.002)$. The current study discovered that the way of insulin storage in poor-controlled hyperglycaemia type 1 diabetes patients, 168 (97.1\%), was good storage of insulin through the transformation from the centre to home, whereas in good-controlled type 1 diabetes patients, $32(88.9 \%)$, was good storage of insulin from the centre to home, with the results showing a significant statistical difference between good-controlled type 1 diabetes patients and poor-controlled hyperglycaemia type 1 diabetes patients was found $(\mathrm{P} .=0.027)$. The current study discovered that compliance with insulin therapy in poor-controlled hyperglycaemia type 1 diabetes patients was 146 (84.4\%), whereas compliance with insulin therapy in good-controlled type 1 diabetes patients was 25 (69.4\%). The results revealed a significant statistical difference between good-controlled type 1 diabetes patients and poorcontrolled hyperglycaemia type 1 diabetes patients was found $(P .=0.034)$ which is confirmed with this study [16]. Compared with patients' compliance with insulin therapy, had 2.38 times (95\% CI $=1.05-5.40)$ higher odds of poor-controlled hyperglycaemia type 1 diabetes patients, and good-controlled type 1 diabetes patients, an indicator of high risk for poor-controlled hyperglycaemia type 1 diabetes patients. The present study found that injection areas that are often used in insulin injection therapy, in poor-controlled hyperglycaemia type 1 diabetes patients, $83(48.0 \%)$ was insulin injection in the arm with insulin therapy, whereas, in goodcontrolled type 1 diabetes patients, $18(50.0 \%)$ was the insulin therapy injection in the more than site, the results showed no significant statistical difference between good-controlled type 1 diabetes and poor-controlled hyperglycaemia type 1 diabetes was found $(\mathrm{P}=0.854)$ which is in agreement with this study [17]. The current study found that the rotation sites with each insulin injection, in diabetic patients with poor-controlled type 1 diabetes patients, $118(68.2 \%)$ did not have a rotation position with each insulin injection treatment, while in diabetics who were good-controlled type 1 diabetes patients, $18(50.0 \%) \%)$ The site was rotated with each insulin injection treatment, the results showed a significant statistical difference between goodcontrolled type 1 diabetes and poor-controlled hyperglycaemia type 1 diabetes was found $(\mathrm{P} .=$ 0.037) which is in agreement with this study [18]. According to the insulin injector among patients with poor-controlled hyperglycaemia of type 1 diabetes patients, $82(47.4 \%)$ was patients self-injected, $90(52.0 \%)$ was injected by parents, $1(0.6 \%)$ was injected by others, while in the control condition of diabetes with type 1 diabetes patients 11 (30.6\%) was patients self-injected $25(69.4 \%)$ was injected by the parent. The results showed no significant statistical difference between good-controlled type 1 diabetes patients, and poor-controlled hyperglycaemia type 1 diabetes patients, was found $(\mathrm{P}=0.153)$. According to the educational level of insulin injector among patients with poor-controlled hyperglycaemia of type 1 diabetes, $84(48.6 \%)$ had a primary school, $76(43.9 \%)$ was at the secondary school level, $13(7.5 \%)$ High educational level (university), while in the control condition of diabetes with type 1 diabetes patients $12(33.3 \%)$ had a primary school, $17(47.3 \%)$ was at the secondary school level, 7 (19.4\%) High level of education (university). Regarding the educational level of insulin injector in poor-controlled hyperglycaemia type 1 diabetes patients and good-controlled type 1 diabetes patients, the results showed a significant statistical difference between poor-controlled hyperglycaemia type 1 diabetes patients and good-controlled type 1 diabetes patients, $(\mathrm{P} .=$ $0.05)$ which agrees with this study [19]. 


\section{References}

[1]. Johnson EL, Feldman H, Butts A, Chamberlain J, Collins B, Doyle-Delgado K, et al. Standards of medical care in diabetes-2020 abridged for primary care providers. Clin Diabetes. 2020;38(1):10-38.

[2]. Fogel JL, Raymond JK. Implementing Telehealth in Pediatric Type 1 Diabetes Mellitus. Pediatr Clin North Am [Internet]. 2020;67(4):661-4.

[3]. Juarez DT, Ma C, Kumasaka A, Shimada R, Davis J. Failure to reach target glycated A1c levels among patients with diabetes who are adherent to their antidiabetic medication. Popul Health Manag. 2014;17(4):218-23.

[4]. Archinkova M, Konstantinova M, Savova R, Iotova V, Petrova C, Kaleva N, et al. Glycaemia control in type 1 diabetes mellitus among Bulgarian children and adolescents: the results from the first and the second national examination of HbAlc. Biotechnol Biotechnol Equip [Internet]. 2017;31(6):1198-203.

[5]. DiMeglio LA, Acerini CL, Codner E, Craig ME, Hofer SE, Pillay K, et al. ISPAD Clinical Practice Consensus Guidelines 2018: Glycaemia control targets and glucose monitoring for children, adolescents, and young adults with diabetes. Pediatr Diabetes. 2018; 19:105-14.

[6]. Eid S, Sas KM, Abcouwer SF, Feldman EL, Gardner TW, Pennathur S, et al. New insights into the mechanisms of diabetic complications: role of lipids and lipid metabolism. Diabetologia. 2019;62(9):1539-49.

[7]. Streisand R, Monaghan M. Young children with type 1 diabetes: Challenges, research, and future directions. Curr Diab Rep. 2014;14(9).

[8]. Almahfoodh D, Alabbood M, Alali A, Mansour A. Epidemiology of type 1 diabetes mellitus in Basrah, Southern Iraq: A retrospective study. Diabetes Res Clin Pract. 2017 Nov 1; 133:104-8.

[9]. Sayed MH, Hegazi MA, Abdulwahed K, Moussa K, El-Deek BS, Gabel H, et al. Risk factors and predictors of uncontrolled hyperglycaemia and diabetic ketoacidosis in children and adolescents with type 1 diabetes mellitus in Jeddah, western Saudi Arabia. J Diabetes. 2017;9(2):190-9.

[10]. Markowitz JT, Butler DA, Volkening LK, Antisdel JE, Anderson BJ, Laffel LMB. Brief screening tool for disordered eating in diabetes: Internal consistency and external validity in a contemporary sample of pediatric patients with type 1 diabetes. Diabetes Care. 2010;33(3):495-500.

[11]. Hanberger L, Åkesson K, Samuelsson U. Glycated haemoglobin variations in paediatric type 1 diabetes: The impact of season, gender and age. Acta Paediatr Int J Paediatr. 2014;103(4):398 403.

[12]. Singh H, Saroch A, Pannu AK, Sachin HJ, Sharma N, Dutta P. Clinical and biochemical profile, precipitants and prognostic factors of diabetic ketoacidosis: A retrospective study from a tertiary care center of north India. Diabetes Metab Syndr Clin Res Rev [Internet]. 2019;13(4):2357-60.

[13]. Rosenbauer J, Dost A, Karges B, Hungele A, Stahl A, Bächle C, et al. Improved metabolic control in children and adolescents with type 1 diabetes: A trend analysis using prospective multicenter data from Germany and Austria. Diabetes Care. 2012;35(1):80-6.

[14]. Al-Agha A, Ocheltree A, Hakeem A. Metabolic control in children and adolescents with insulindependent diabetes mellitus at King Abdul-Aziz university hospital. JCRPE J Clin Res Pediatr Endocrinol. 2011;3(4):202-7.

[15]. Craig ME, Jones TW, Silink M, Ping YJ. Diabetes care, Glycaemia control, and complications in children with type 1 diabetes from Asia and the Western Pacific Region. J Diabetes Complications. 2007;21(5):280-7.

[16]. Alahmadi S, Ragaban A, Alblowi S, Aljumail E, Zarif H. Diabetic ketoacidosis; Annual Incidence and Precipitating Factors at King Abdulaziz Medical city, Jeddah. 2018;72(July):4831-5.

[17]. Tsadik AG, Atey TM, Nedi T, Fantahun B, Feyissa M. Effect of Insulin-Induced Lipodystrophy on Glycaemia Control among Children and Adolescents with Diabetes in Tikur Anbessa Specialized Hospital, Addis Ababa, Ethiopia. J Diabetes Res. 2018;2018.

[18]. Cunningham MT, McKenna M. Lipohypertrophy in insulin-treated diabetes: Prevalence and associated risk factors. J Diabetes Nurs. 2013;17(9):340-3.

[19]. Tsadik AG, Atey TM, Nedi T, Fantahun B, Feyissa M. Effect of Insulin-Induced Lipodystrophy on Glycaemia Control among Children and Adolescents with Diabetes in Tikur Anbessa Specialized Hospital, Addis Ababa, Ethiopia. J Diabetes Res. 2018;2018. 